Pacific Journal of Mathematics

STRICTLY CYCLIC OPERATOR ALGEBRAS ON A BANACH

MARY RODRIGUEZ EM 


\title{
STRICTLY CYCLIC OPERATOR ALGEBRAS ON A BANACH SPACE
}

\author{
MARY R. EMBRY
}

\begin{abstract}
A strictly cyclic operator algebra $\mathscr{A}$ on a complex Banach space $X(\operatorname{dim} X \geqq 2)$ is a uniformly closed subalgebra of $\mathscr{L}(X)$ such that $\mathscr{A} x=X$ for some $x$ in $X$. If $A x=0, A \in \mathscr{A}$ implies that $A=0$, then $\mathscr{A}$ is separated. In this paper it is shown that i) if $\mathscr{A}$ is strictly cyclic and separated, then $\mathscr{A}$ has a maximal, proper, closed invariant subspace, ii) if $\mathscr{A}$ is strictly cyclic, then $\mathscr{A}^{\prime}$ (the commutant of $\mathscr{A}$ ) is intransitive, iii) if $A \in \mathscr{L}(X), A \neq z I$ and $\{A\}^{\prime}$ is strictly cyclic, then $A$ has a hyperinvariant subspace, and iv) that a transitive subalgebra of $\mathscr{L}(X)$, containing a strictly cyclic algebra which contains $I$, is strongly dense in $\mathscr{L}(X)$. An example demonstrates the existence of abelian and nonabelian strictly cyclic, separated operator algebras on each Banach space of dim $\geqq 2$. A second example classifies the strictly cyclic weighted shifts on $l_{1}$ and shows that the commutant of each such operator consists of uniform limits of polynomials of the operator.

If $\mathscr{A}$ is a strictly cyclic operator algebra on $X$ and $\mathscr{A} x=X$, then $x$ is called a strictly cyclic vector for $\mathscr{A}$. If it is also true that $A x=0$ implies $A=0$ for $A$ in $\mathscr{A}$, we say that $x$ is a separating vector for $\mathscr{A}$. For many results in this paper it is not required that $\mathscr{A}$ be separated or that the identity operator $I$ on $X$ be an element of $\mathscr{A}$.
\end{abstract}

$\mathscr{L}(X)$ is the set of all continuous linear operators on $X$. If $\mathscr{B} \subset \mathscr{L}(X)$, then the commutant of $\mathscr{B}$ is $\mathscr{B}^{\prime}=\{E: E \in \mathscr{L}(X)$ and $E B=B E$ for all $B$ in $\mathscr{B}\}$ and $\mathscr{B}^{\prime \prime}=\left(\mathscr{B}^{\prime}\right)^{\prime}$. We shall use the terminology of "invariant" and "transitive" as follows: if $M \subset X$ and $\mathscr{B} \subset \mathscr{L}(X)$, then (i) $M$ is invariant under $\mathscr{B}$ if $\mathscr{B} M=\{B m: B \in \mathscr{B}$ and $m \in M\} \subset M$, (ii) $M$ is an invariant subspace for $\mathscr{B}$ if $M$ is invariant under $\mathscr{B}$ and $M$ is a closed, nontrivial $(\neq\{0\}, X)$ linear subspace of $X$, (iii) $\mathscr{B}$ is transitive if $\mathscr{B}$ has no invariant subspaces and intransitive if $\mathscr{B}$ has an invariant subspace. Further, if $A \in \mathscr{L}(x)$ and $\{A\}^{\prime}$ is intransitive, then each invariant subspace of $\{A\}^{\prime}$ is called a hyperinvariant subspace of $A$. Finally an invariant subspace of $\mathscr{B}$ is maximal if it is not properly contained in another invariant subspace of $\mathscr{B}$.

If $A \in \mathscr{L}(X)$, then ker $A$ denotes the null space of $A, \mathscr{R}(A)$ the closure of the range of $A$, and $\sigma(A)$ the spectrum of $A . \mathscr{A}_{A}$ is the weakly closed algebra generated by $A$ and $I$. If $M \subset X$, then $\bar{M}$ denotes the closure of $M$ in the norm topology of $X$. 
2. A basic lemma. Almost all of the results in this paper concerning invariant subspaces of a strictly cyclic operator algebra $\mathscr{A}$ stem from the following lemma.

Lemma 2.1. Let $x$ be a strictly cyclic vector for $\mathscr{A}$. Then

(i) there exists a positive number $K$ such that $\|E\| \leqq K\|E x\|$ for all $E$ in $\mathscr{A}^{\prime}$,

(ii) if $\lim _{n \rightarrow \infty} x_{n}=0$, there exists a sequence $\left\{A_{n}\right\}$ of elements of $\mathscr{A}$ such that $A_{n} x=x_{n}$ and $\lim _{n \rightarrow \infty}\left\|A_{n}\right\|=0$,

(iii) if $x$ is separating for $\mathscr{A}$, there exists a positive number $K$ such that $\|A\| \leqq K\|A x\|$ for all $A$ in $\mathscr{A}$.

Proof. In the proof of each of the three statements we shall make use of the mapping $T$ of $\mathscr{A}$ onto $X$ defined by $T(A)=A x$. Note that $T$ is continuous, linear and onto. In Case (iii) $T$ is also one-to-one and hence by the Open Mapping Theorem has a continuous linear inverse. Thus $\|A\| \leqq K\|A x\|$ for some positive $K$ and all $A$ in $\mathscr{A}$.

Consider now Assertion (i). Since $T$ is onto, we know that $T^{*}$ has a continuous inverse and there exists a positive number $K$ such that $\left\|x^{*}\right\| \leqq K\left\|T^{*} x^{*}\right\|$ for all continuous linear functionals $x^{*}$ on $X$. Assume now that $E \in \mathscr{A}^{\prime}$ and that $A \in \mathscr{A},\|A\|=1$. The following computation will lead to the desired conclusion:

$$
\begin{aligned}
\left|T^{*}\left(E^{*} x^{*}\right)(A)\right| & =\left|\left(E^{*} x^{*}\right)(A x)\right|=\left|x^{*}(E A x)\right| \\
& =\left|x^{*}(A E x)\right|=\left|\left(A^{*} x^{*}\right)(E x)\right| \\
& \leqq\left\|A^{*} x^{*}\right\|\|E x\| \leqq\left\|x^{*}\right\|\|E x\| .
\end{aligned}
$$

Thus

$$
\begin{aligned}
\left\|E^{*} x^{*}\right\| & \leqq K\left\|T^{*}\left(E^{*} x^{*}\right)\right\| \\
& =K \sup \left\{\left|T^{*}\left(E^{*} x^{*}\right)(A)\right|: A \in \mathscr{A},\|A\|=1\right\} \\
& \leqq K\left\|x^{*}\right\|\|E x\|,
\end{aligned}
$$

and finally $\|E\|=\left\|E^{*}\right\| \leqq\|K\| E x \|$.

To prove (ii) we shall consider the quotient space $\mathscr{A} / M$ where $M=\operatorname{ker} T$ and the mapping $T^{\prime}$ of $\mathscr{A} / M$ onto $X$ defined by $T^{\prime}[A]=$ $A x$. Since $T^{\prime}$ is one-to-one, onto and continuous, there exists a positive number $K$ such that $\|[A]\| \leqq K\left\|T^{\prime}[A]\right\|=K\|A x\|$. Assume that $\lim _{n \rightarrow \infty} x_{n}=0$ and let $E_{n} x=x_{n}, E_{n} \in \mathscr{A}$. The preceding inequality implies that $\lim _{n \rightarrow \infty}\left\|\left[E_{n}\right]\right\|=0$. Since $\left\|\left[E_{n}\right]\right\|=\inf \left\{\left\|A_{n}\right\|: A_{n} x=E_{n} x\right\}$, it is now obvious that we can choose a sequence $\left\{A_{n}\right\}$ with $A_{n}$ in $\left[E_{n}\right]$ and $\lim _{n \rightarrow \infty}\left\|A_{n}\right\|=0$. The proof is complete.

3. Invariant subspace theorems. Since $\mathscr{L}(X)$ is a strictly cyclic operator algebra, it is obviously not the case that every strictly cyclic 
operator algebra has an invariant subspace. However, if an operator algebra $\mathscr{A}$ is both strictly cyclic and separated, then not only can we show it to be intransitive, but we can show the following stronger result.

THEOREM 3.1. Every strictly cyclic, separated operator algebra \& has a maximal invariant subspace.

Proof. We shall make use of the terminology and results on Banach algebras found in [4, pp. 680-705]. Let $x$ be a strictly cyclic, separating vector for $\mathscr{A}$ and let $A_{0}$ be the unique element of $\mathscr{A}$ such that $A_{0} x=x$. Then $A A_{0} x=A x$ for each $A$ in $\mathscr{A}$ and since $x$ is separating, we have $A A_{0}=A$. In particular $A_{0}$ is a nonzero idempotent. Thus $A_{0}$ is not in the radical of $\mathscr{A}$ and by [4, Theorem 24.9.2, p. 704], $\mathscr{A}$ contains a left regular maximal ideal $N$. By definition of "regular maximal", $N$ is neither the zero ideal nor all of $\mathscr{A}$ and thus by $[4$, Theorem $24.6 .4, \mathrm{p} .695] N$ is a proper closed maximal left ideal of $\mathscr{A}$. Let $M=\{A x: A \in N\} . M$ is invariant under $\mathscr{A}$ and Lemma 2.1 (iii) guarantees that $M$ is a maximal invariant subspace for $\mathscr{A}$.

Theorem 3.1 is obviously of interest in the general invariant subspace problem, for if $\mathscr{A}$ satisfies the hypotheses of the theorem and operates on a reflexive space $X$ and if $M$ is a maximal invariant subspace for $\mathscr{A}$, then $M^{\perp}$ is a minimal invariant subspace for $\mathscr{A}^{*}$. (By $M^{\perp}$ we mean the set of continuous linear functionals $x^{*}$ on $X$ such that $x^{*}(M)=0$, and $\mathscr{A}^{*}$ is the set of adjoints of elements of $\mathscr{A}$.)

We now return to the problem of invariant subspaces and strictly cyclic, but not necessarily separated, operator algebras.

THeOREm 3.2. If $\mathscr{A}$ is strictly cyclic, then $\mathscr{A}^{\prime}$ is intransitive.

Proof. We may assume that there is a nonzero, noninvertible element $E$ of $\mathscr{A}^{\prime}$ (for otherwise $\mathscr{A}^{\prime}=\{z I\}$ and the assertion is trivial). Let $M=\mathscr{A}^{\prime} E x$, where $x$ is a strictly cyclic vector for $\mathscr{A}$. If $x \in \bar{M}$, then $x=\lim _{n \rightarrow \infty} E_{n} E x$ for some sequence $\left\{E_{n}\right\}$ in $\mathscr{A}^{\prime}$. Thus by Lemma 2.1 (i) $\lim _{n \rightarrow \infty}\left\|E_{n} E-I\right\|=0$, and for $n$ sufficiently large $E_{n} E$ is invertible. Consequently, $E_{n}$ is onto, but not one-to-one (since $E$ is not invertible). Let $N=\mathscr{A}^{\prime} E_{n} x . A$ repetition of the same argument shows that $x \notin \bar{N}$. Thus either $\bar{M}$ or $\bar{N}$ is an invariant subspace for $\mathscr{A}^{\prime}$.

COROLlaRY 3.3. If $\mathscr{B} \subset \mathscr{L}(X)$ and $\mathscr{B}$ ' is strictly cyclic, then $\mathscr{B}$ is intransitive. 
Proof. By Theorem $3.2 \mathscr{B}^{\prime \prime}$ is intransitive and since $\mathscr{B} \subset \mathscr{B} "$, we know that $\mathscr{B}$ is intransitive.

Before presenting the rest of the invariant subspace theorems we shall prove a series of lemmas which parallel those proved by Lambert in [6]. Throughout the remainder of this section we shall assume that $x$ is a strictly cyclic vector for $\mathscr{A}$ and that $\mathscr{A}$ contains the identity operator $I$. After this development we shall be able to show that if $\mathscr{B}$ satisfies the hypotheses of Corollary 3.3 and $\mathscr{B} \not \subset\{z I\}$, then $\mathscr{B}^{\prime}$ is intransitive.

Lemma 3.4. If $M \subset X$, $\mathscr{A} M \subset M$ and $x \in \bar{M}$, then $M=X$.

Proof. We shall show that $x \in M$ and thus $X=\mathscr{A} x \subset \mathscr{A} M \subset M$. Let $\left\{x_{n}\right\}$ be a sequence in $M$ such that $\lim _{n \rightarrow \infty} x_{n}=x$. By Lemma 3.1 (ii) we may assume the existence of a sequence $\left\{A_{n}\right\}$ in $\mathscr{A}$ such that $A_{n} x=x-x_{n}$ and $\lim _{n \rightarrow \infty}\left\|A_{n}\right\|=0$. Thus for $n$ sufficiently large, $\left\|A_{n}\right\|<1$ and $\left(I-A_{n}\right)^{-1}=\sum_{k=0}^{\infty}\left(A_{n}\right)^{k}$. Therefore $\left(I-A_{n}\right)^{-1} \in \mathscr{A}$ and since $\left(I-A_{n}\right) x=x_{n}$, we have $x=\left(I-A_{n}\right)^{-1} x_{n} \in M$.

We say that a linear transformation $T$ commutes with $\mathscr{A}$ if and only if the domain $\mathscr{D}(T)$ of $T$ is invariant under $\mathscr{A}$ and $A T y=$ $T A y$ for all $y$ in $\mathscr{D}(T)$ and all $A$ in $\mathscr{A}$.

LEMMA 3.5. If $T$ is a densely defined linear transformation which commutes with $\mathscr{A}$, then $T$ is everywhere defined and continuous.

Proof. Since $\mathscr{D}(T)$ is dense in $X$, we know by Lemma 3.4 that $\mathscr{D}(T)=X$. We shall now prove that $T$ is closed and thus continuous by the Closed Graph Theorem. Assume that $\lim _{n \rightarrow \infty} x_{n}=y$ and $\lim _{n \rightarrow \infty} T x_{n}=w$. By Lemma 2.1 (ii) we may assume the existence of a sequence $\left\{A_{n}\right\}$ in $\mathscr{A}$ such that $A_{n} x=\left(x_{n}-y\right)$ and $\lim _{n \rightarrow \infty}\left\|A_{n}\right\|=0$. Then $w=\lim _{n \rightarrow \infty} T x_{n}=\lim _{n \rightarrow \infty} T\left(A_{n} x+y\right)=\lim _{n \rightarrow \infty}\left(A_{n} T x+T y\right)=T y$, proving that $T$ is closed.

Lemma 3.6. If $E \in \mathscr{A}^{\prime}$ and $z \in \sigma(E)$, then either $\operatorname{ker}(z I-E) \neq$ $\{0\}$ or $\mathscr{R}(z I-E) \neq X$.

Proof. Assume that $z I-E$ is one-to-one. Then $(z I-E)^{-1}$ is a linear transformation which commutes with $\mathscr{A}$. Since $z \in \sigma(E)$, $z I-E$ is not onto and thus by Lemma $3.5(z I-E)^{-1}$ is not densely defined: that is, $\mathscr{R}(z I-E) \neq X$.

In [2] it was shown that if $A \in \mathscr{L}(X)$ and $\{A\}^{\prime}$ is strictly cyclic, then $A$ has an invariant subspace. We can now generalize that theorem. 
THEOREM 3.7. If $A$ is not a scalar multiple of $I$ and $\{A\}^{\prime}$ is strictly cyclic, then $A$ has a hyperinvariant subspace.

Proof. Let $z \in \sigma(A)$. Applying Lemma 3.6 to $\{A\}^{\prime}$, we see that either $\operatorname{ker}(z I-A) \neq\{0\}$ or $\mathscr{R}(z I-A) \neq X$. Each of these sets is invariant under $\{A\}^{\prime}$ and thus in either case $\{A\}^{\prime}$ has an invariant subspace.

Assume now that $\mathscr{B} \subset \mathscr{L}(X), \mathscr{B} \not \subset\{z I\}$ and $\mathscr{\mathscr { B }} '$ is strictly cyclic. Then some element $A$ of $\mathscr{B}$ satisfies the hypotheses of Theorem 3.7 and has a hyperinvariant subspace. Thus since $\mathscr{B}^{\prime} \subset\{A\}^{\prime}, \mathscr{\mathscr { B }}{ }^{\prime}$ has an invariant subspace and we have arrived at the promised adjunct to Theorem 3.3.

In [1] Arveson proves that a transitive algebra $\mathscr{T}$ of operators on a Hilbert space $X$ containing a maximal abelian self-adjoint algebra is weakly dense in $\mathscr{L}(X)$. In [6] Lambert shows that the same conclusion is true if $\mathscr{T}$ contains a strictly cyclic abelian algebra. To these results we add the following Banach space application of Arveson's results.

THEOREM 3.8. If $\mathscr{T}$ is a transitive subalgebra of $\mathscr{L}(X)$ and $\mathscr{A} \subset \mathscr{G}$, then $\mathscr{T}$ is strongly dense in $\mathscr{L}(X)$.

Proof. Assume that $\mathscr{G}$ is a transitive subalgebra of $\mathscr{L}(X)$. It follows from [1, p. 636 and Cor. 2.5, p. 641] that $\mathscr{G}$ is strongly dense in $\mathscr{E}(X)$ if each densely defined linear transformation commuting with $\mathscr{T}$ is everywhere defined and is a scalar multiple of $I$. We shall show that the latter occurs. If $T$ is densely defined and commutes with $\mathscr{T}, T$ also commutes with $\mathscr{A}$. Thus by Lemma 3.5 $T$ is everywhere defined and continuous. Now let $z \in \sigma(T)$. Both ker $(z I-T)$ and $\mathscr{R}(z I-T)$ are invariant under $\mathscr{Y}$. By Lemma 3.6 either $\operatorname{ker}(z I-T) \neq\{0\}$ or $\mathscr{R}(z I-T) \neq X$. Since $\mathscr{T}$ is transitive, the first case implies that $\operatorname{ker}(z I-T)=X$ and the second that $\mathscr{R}(z I-T)=\{0\}$. In either case $z I-T=0$ and the proof is complete.

4. Examples. In the first example we shall show that on every complex Banach space $X$ there exists an abelian strictly cyclic, separated algebra of operators, and if $\operatorname{dim} X \geqq 2$, there exists a nonabelian strictly cyclic, separated operator algebra. The technique used in this example is essentially the same as that used by Lambert in [6]. In the second example we shall characterize the strictly cyclic one-sided weighted shifts $A$ on $l_{1}$. Our characterization is the same as that given in [3, Theorem 21, p. 78] for two-sided shifts on $l_{1}$. We present this example again because of the different context and because we are able to characterize $\mathscr{A}_{A}$. 
ExAmple 1. Let $X$ be a Banach space, $x_{0} \in X, x_{0} \neq 0$. Let each of $x^{*}$ and $y^{*}$ be a continuous linear functional on $X$ such that $x^{*}\left(x_{0}\right)=$ $y^{*}\left(x_{0}\right)=1$. For each $x$ in $X$ define $A_{x}$ by

$$
A_{x} y=x^{*}(x)\left[y-y^{*}(y) x_{0}\right]+y^{*}(y) x .
$$

Let $\mathscr{A}=\left\{A_{x}: x \in X\right\}$.

Straightforward computation shows that

(1) each $A_{x} \in \mathscr{L}(X)$,

(2) $\mathscr{A}$ is linear,

(3) $A_{z} A_{x}=A_{A_{z} x}$ for $x$ and $z$ in $X$, so that $\mathscr{A}$ is an algebra,

(4) $A_{x} x_{0}=x$ for each $x$ in $X$, so that $\mathscr{A}$ is strictly cyclic and separated, and

(5) if $T$ is in the uniform closure of $\mathscr{A}$ in $\mathscr{L}(X)$, then $T=$ $A_{T x_{0}}$ so that $\mathscr{A}$ is uniformly closed.

If $\operatorname{dim} X \geqq 3$, a simple argument shows that $\mathscr{A}$ is abelian if and only if $x^{*}=y^{*}$. However, if $\operatorname{dim} X=2$, we have a different situation which we shall state as a general proposition: if $\mathscr{A}$ is a strictly cyclic, separated algebra of operators on a Banach space of dimension 2 and $I \in \mathscr{A}$, then $\mathscr{A}$ is abelian.

Proof. Let $x_{0}$ be a strictly cyclic, separating vector for $\mathscr{A}$ and let $x_{1}$ be any element of $X$ such that $\left\{x_{0}, x_{1}\right\}$ is a basis for $X$. Let $A \in \mathscr{A}, A x_{0}=x_{1}$. Then using the fact that $\mathscr{A}$ is strictly cyclic and separated, it is an easy task to show that $\mathscr{A}$ is the algebra generated by $I$ and $A$ and hence is abelian.

An example of a strictly cyclic, separated, nonabelian algebra $\mathscr{A}$ on a two dimensional vector space is $\mathscr{A}=\left\{\left(\begin{array}{ll}a & 0 \\ b & 0\end{array}\right): a, b\right.$ complex numbers\}.

EXAMPLE 2. Let $l_{1}$ be the Banach space of absolutely summable sequences $y=\left\{y_{n}\right\}_{n=0}^{\infty}$ of complex numbers. $\left\{e_{n}\right\}_{n=0}^{\infty}$ is the natural basis for $l_{1}$. Let $\left\{a_{n}\right\}_{n=1}^{\infty}$ be a sequence of nonzero complex numbers and let $A$ be the linear transformation defined by $A e_{n}=a_{n+1} e_{n+1}(n \geqq 0)$ and extended linearly to all finite linear combinations of $\left\{e_{n}\right\}$. For convenience in manipulation we define $b_{0}=1$ and $b_{n}=\prod_{i=1}^{n} a_{i}$ for $n \geqq 1$.

Proposition. A can be extended to a continuous linear operator on $l_{1}$ such that $e_{0}$ is a strictly cyclic, separating vector for $\mathscr{A}_{A}$ if and only if

$$
\sup _{i, n}\left|\frac{b_{i+n}}{b_{i} b_{n}}\right|=K<\infty .
$$

Furthermore, in this case 


$$
\mathscr{A}_{A}=\{A\}^{\prime}=\left\{\sum_{n=0}^{\infty} \frac{y_{n}}{b_{n}} A^{n}:\left\{y_{n}\right\} \in l_{1}\right\}
$$

and thus every element of $\{A\}^{\prime}$ is the uniform limit of a sequence of polynomials in $A$.

Proof. Note that $A^{n} e_{i}=\left(b_{i+n} / b_{i}\right) e_{i+n}$ for $n, i \geqq 0$. Assume first that $A$ has a continuous extension to $l_{1}$ and that $e_{0}$ is a strictly cyclic, separating vector for $\mathscr{A}_{A}$. By Lemma 2.1 (iii) there exists a $K>0$ such that $\|E\| \leqq K\left\|E e_{0}\right\|$ for all $E$ in $\mathscr{A}_{A}$. Therefore for each $i$ and $n$

$$
\left|\frac{b_{i+n}}{b_{n} b_{i}}\right|=\left\|\frac{1}{b_{n}} A^{n} e_{i}\right\| \leqq \frac{1}{\left|b_{n}\right|} K\left\|A^{n} e_{0}\right\|=\frac{1}{\left|b_{n}\right|} K\left|\frac{b_{n}}{b_{0}}\right|=K .
$$

and $(*)$ holds.

Assume now that $(*)$ holds. First we shall prove that $A$ is bounded. Let $y=\left\{y_{n}\right\}$ be an element of $l_{1}$ with at most a finite number of nonzero terms. Then

$$
\begin{aligned}
\|A y\| & =\left\|A\left(\sum y_{n} e_{n}\right)\right\|=\left\|\sum y_{n} A e_{n}\right\| \\
& =\left\|\sum y_{n} \frac{b_{n+1}}{b_{n}} e_{n+1}\right\| \leqq K\left|b_{1}\right| \sum\left|y_{n}\right|=K\left|b_{1}\right|\|y\|,
\end{aligned}
$$

showing that $A$ is bounded on a dense linear manifold of $l_{1}$ and has a continuous extension to all of $l_{1}$.

Now let $x=\left\{x_{n}\right\}$ and $y=\left\{y_{n}\right\}$ be elements of $l_{1}$ and $p$ and $q$ be integers, $p \leqq q$. Then

$$
\begin{aligned}
\left\|\sum_{n=p}^{q} \frac{y_{n}}{b_{n}} A^{n} x\right\| & =\left\|\sum_{n=p}^{q} \frac{y_{n}}{b_{n}} \sum_{i=0}^{\infty} x_{i} \frac{b_{i+n}}{b_{i}} e_{i+n}\right\| \\
& =\left\|\sum_{i=0}^{\infty} x_{i} \sum_{n=p}^{q} \frac{b_{i+n}}{b_{n} b_{i}} y_{n} e_{i+n}\right\| \leqq\|x\| K \sum_{n=p}^{q}\left|y_{n}\right|,
\end{aligned}
$$

and consequently, $\left\|\sum_{n=p}^{q}\left(y_{n} / b_{n}\right) A^{n}\right\| \leqq K \sum_{n=p}^{q}\left|y_{n}\right|$. Therefore by the completeness of $\mathscr{L}\left(l_{1}\right) \sum_{n=0}^{\infty}\left(y_{n} / b_{n}\right) A^{n} \in \mathscr{L}\left(l_{1}\right)$ for each $\left\{y_{n}\right\}$ in $l_{1}$. Let $\mathscr{B}=\left\{\sum_{n=0}^{\infty}\left(y_{n} / b_{n}\right) A^{n}:\left\{y_{n}\right\} \in l_{1}\right\}$. Note that

$$
\sum_{n=0}^{\infty} \frac{y_{n}}{b_{n}} A^{n} e_{0}=\sum_{n=0}^{\infty} \frac{y_{n}}{b_{n}} \frac{b_{n}}{b_{0}} e_{n}=\sum_{n=0}^{\infty} y_{n} e_{n}=y
$$

so that $\mathscr{B} e_{0}=l_{1}$. Since $\mathscr{B} \subset \mathscr{A}_{A}, e_{0}$ is strictly cyclic for $\mathscr{A}_{A}$ and thus $e_{0}$ is also separating for $\{A\}^{\prime}$. However since $\mathscr{B} \subset \mathscr{A}_{A} \subset\{A\}^{\prime}, \mathscr{B} e_{0}=l_{1}$ and $e_{0}$ is separating for $\{A\}^{\prime}$, it is immediate that $\mathscr{B}=\mathscr{A}_{A}=\{A\}^{\prime}$ and our proof is complete.

Operators such as the one discussed in the preceding proposition are called (one-sided) weighted shifts. It is easy to see by condition 
(*) that every weighted shift on $l_{1}$ with monotone nonincreasing weights is strictly cyclic. An example of a strictly cyclic weighted shift with nonmonotone weights is $a_{2 i}=1$ and $a_{2 i+1}=1 / 2$. Other such shifts are discussed in [3].

Weighted shifts on separable infinite dimensional Hilbert space have the subject of several recently published papers. In [8] Shields and Wallen show that if $A$ is a weighted shift with nonzero weights, then every operator commuting with $A$ is the limit in the strong topology of a sequence of polynomials in $A$. In [7] Nordgren shows that every element of the commutant of a Donoghue operator $A$ is the uniform limit of a sequence of polynomials in $A$; Lambert [5] generalizes Nordgren's result by showing that every Donoghue operator is a strictly cyclic weighted shift and that for each strictly cyclic weighted shift $A$ the commutant consists of uniform limits of polynomials in $A$. This parallels the result in our example.

5. Structure of $\mathscr{A}^{\prime}$. If $x$ is a strictly cyclic vector for $\mathscr{A}$, then certainly $x$ is separating for $\mathscr{A}^{\prime}$ and by Lemma 2.1 (i) $\mathscr{A}^{\prime} x$ is a closed linear subspace of $X$. However, little else can be said about the structure of $\mathscr{A}^{\prime}$. Thus in this section we shall assume that $\mathscr{A}$ has a strictly cyclic, separating vector $x$. For each $y$ in $X$ let $A_{y}$ be the unique element of $\mathscr{A}$ such that $A_{y} x=y$. Note that $A_{x}$ is an idempotent.

THEOREM 5.1. EE $\mathscr{A}^{\prime}$ if and only if there exists an $A$ in $\mathscr{A}$ such that $E y=A_{y} A x$ for each $y$ in $Y$. That is, $\mathscr{A}^{\prime}$ is the set of all right multiplications of $\mathscr{A}$ by elements of $\mathscr{A}$.

Proof. If $E \in \mathscr{O}^{\prime}$, then $E y=E A_{y} x=A_{y} E x=A_{y} A_{E x} x$. Conversely, if $E$ is the linear transformation defined by $E y=A_{y} A x$, then by Lemma 2.1 (iii) $\|E y\| \leqq\left\|A_{y}\right\| A x\|\leqq K\| A_{y} x\|\| A x\|=K\| y\|\| A x \|$ and $E$ is bounded. Note that if $y$ and $z$ are in $X$, then $A_{y} A_{z} x=$ $A_{y} z=A_{A_{y} z} x$ so that $A_{y} A_{z}=A_{A_{y} z}$. Therefore $A_{z} E y=A_{z} A_{y} A x=A_{A_{z} y} A x=$ $E A_{z} y$, proving that $E \in \mathscr{A}^{\prime}$.

THEOREM 5.2. $x$ is a strictly cyclic separating vector for $\mathscr{A}^{\prime}$ if and only if $I \in \mathscr{A}$. In this case $\mathscr{A}=\mathscr{L}^{\prime \prime}$.

Proof. In any case $x$ is a separating vector for $\mathscr{A}^{\prime}$ since $x$ is a cyclic vector for $\mathscr{A}$. By Theorem 5.1

$$
\mathscr{A}^{\prime} x=\left\{E x: E y=A_{y} A x, A \in \mathscr{A}\right\}=A_{x}(\mathscr{A} x)=A_{x}(X) \text {. }
$$

Thus $x$ is strictly cyclic for $\mathscr{L}^{\prime}$ only in case the idempotent $A_{x}$ maps $X$ onto $X$. This last occurs only if $A_{x}=I$. 
Assume now that $I \in \mathscr{A}$. Then since $x$ is a strictly cyclic, separating vector for $\mathscr{A}^{\prime}$ and $I \in \mathscr{A}^{\prime}$, we know that $x$ is also a strictly cyclic, separating vector for $\mathscr{A}^{\prime \prime}$. Therefore $\mathscr{A}=\mathscr{A}^{\prime \prime}$ since $\mathscr{A} \subset \mathscr{A} "$, $x$ is strictly cyclic for $\mathscr{A}$, and $x$ is separating for $\mathscr{A}^{\prime \prime}$.

One consequence of Theorem 5.2 is that a uniformly closed, strictly cyclic, separated operator algebra containing $I$ is also closed in the weak operator topology. A second consequence is that an operator algebra $\mathscr{A}$ satisfying these conditions is abelian if and only if $\mathscr{A}^{\prime}$ is abelian. In [5] Lambert shows that an abelian strictly cyclic, separated operator algebra is maximal abelian. Thus if $\mathscr{A}^{\prime}$ is abelian, $\mathscr{A}^{\prime}=\mathscr{A}^{\prime \prime}$ and therefore by Theorem $5.2 \mathscr{A}=\mathscr{A}^{\prime}$. If we apply this last conclusion to $\{A\}^{\prime}$, we arrive at the assertion that if $\{A\}^{\prime}$ is strictly cyclic and separated, then $\{A\}^{\prime}$ is abelian (since $\{A\}^{\prime \prime}$ is always abelian).

Acknowledgments. I should like to express my gratitude to Alan Lambert for a stimulating correspondence on strictly cyclic operator algebras. He has indicated to me that he and D. A. Herrero also obtained the results in Theorems 5.1 and 5.2. To Ralph Gellar I should like to express my appreciation for pointing out to me the connection between left ideals of $\mathscr{A}$ and invariant subspaces of $\mathscr{A}$ and the identification of elements of $\mathscr{C}^{\prime}$ with right multiplications by elements of $\mathscr{\%}$. To John Hedstrom I should like to express my appreciation for his help in the proof of Theorem 3.1.

Addendum. After the completion of this manuscript, the author received two preprints from D. A. Herrero in which he has proved some of the same results. In Theorem 1 of "Operator algebras of finite strict multiplicity", Herrero proves Lemmas 3.4-3.6 of this paper. In Theorem 2 of "Algebras de operadores transitivas que contienen una subalgebra de multiplicidad estricta finita" he proves Theorem 3.8 of this paper. The author expresses her gratitude to Professor Herrero for having communicated these results.

\section{REFERENCES}

1. W. B. Arveson, A density theorem for operator algebras, Duke Math. J., 34 (1967), 635-647.

2. M. R. Embry, An invariant subspace theorem, Proc. Amer. Math. Soc., (to appear).

3. R. Gellar, Cyclic vectors and parts of the spectrum of a weighted shift, Trans. Amer. Math. Soc., 146 (1969), 69-85.

4. E. Hille and R. S. Phillips, Functional Analysis and Semigroups, American Mathematical Society, Providence, R. I., 1957.

5. A. Lambert, Strictly cyclic weighted shifts, Proc. Amer. Math. Soc., 29 (1971), 331-336.

6. - Strictly cyclic operator algebras, Pacific J. Math., (to appear). 
7. E. Nordgren, Closed operators commuting with a weighted shift, Proc. Amer. Math. Soc., 24 (1970), 424-428.

8. A. L. Shields and L. J. Wallen, The commutants of certain Hilbert space operators, Indiana Univ. Math. J., 20 (1971), 777-788.

Received November 18, 1971.

University of North Carolina at Charlotte 


\section{PACIFIC JOURNAL OF MATHEMATICS}

\section{EDITORS}

\author{
H. SAMELson \\ Stanford University \\ Stanford, California 94305 \\ C. R. HоввY \\ University of Washington \\ Seattle, Washington 98105
}

J. DugundJI

Department of Mathematics

University of Southern California

Los Angeles, California 90007

RICHARD ARENS

University of California

Los Angeles, California 90024

\section{ASSOCIATE EDITORS}
E. F. BeCKENBACH
B. H. NEUMANN
F. WOLF
K. YoshidA

\section{SUPPORTING INSTITUTIONS}

UNIVERSITY OF BRITISH COLUMBIA

CALIFORNIA INSTITUTE OF TECHNOLOGY

UNIVERSITY OF CALIFORNIA

MONTANA STATE UNIVERSITY

UNIVERSITY OF NEVADA

NEW MEXICO STATE UNIVERSITY

OREGON STATE UNIVERSITY

UNIVERSITY OF OREGON

OSAKA UNIVERSITY

\author{
UNIVERSITY OF SOUTHERN CALIFORNIA \\ STANFORD UNIVERSITY \\ UNIVERSITY OF TOKYO \\ UNIVERSITY OF UTAH \\ WASHINGTON STATE UNIVERSITY \\ UNIVERSITY OF WASHINGTON

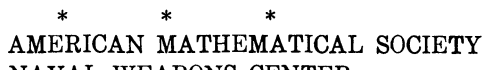 \\ NAVAL WEAPONS CENTER
}

The Supporting Institutions listed above contribute to the cost of publication of this Journal, but they are not owners or publishers and have no responsibility for its content or policies.

Mathematical papers intended for publication in the Pacific Journal of Mathematics should be in typed form or offset-reproduced, (not dittoed), double spaced with large margins. Underline Greek letters in red, German in green, and script in blue. The first paragraph or two must be capable of being used separately as a synopsis of the entire paper. The editorial "we" must not be used in the synopsis, and items of the bibliography should not be cited there unless absolutely necessary, in which case they must be identified by author and Journal, rather than by item number. Manuscripts, in duplicate if possible, may be sent to any one of the four editors. Please classify according to the scheme of Math. Rev. Index to Vol. 39. All other communications to the editors should be addressed to the managing editor, Richard Arens, University of California, Los Angeles, California, 90024.

50 reprints are provided free for each article; additional copies may be obtained at cost in multiples of 50 .

The Pacific Journal of Mathematics is issued monthly as of January 1966. Regular subscription rate: $\$ 48.00$ a year (6 Vols., 12 issues). Special rate: $\$ 24.00$ a year to individual members of supporting institutions.

Subscriptions, orders for back numbers, and changes of address should be sent to Pacific Journal of Mathematics, 103 Highland Boulevard, Berkeley, California, 94708.

PUBLISHED BY PACIFIC JOURNAL OF MATHEMATICS, A NON-PROFIT CORPORATION

Printed at Kokusai Bunken Insatsusha (International Academic Printing Co., Ltd.), 270, 3-chome Totsuka-cho, Shinjuku-ku, Tokyo 160, Japan. 


\section{Pacific Journal of Mathematics}

\section{Vol. 45, No. $2 \quad$ October, 1973}

Kenneth Paul Baclawski and Kenneth Kapp, Induced topologies for quasigroups and loops ............................................. 393

D. G. Bourgin, Fixed point and $\min -\max$ theorems $\ldots \ldots \ldots \ldots \ldots \ldots \ldots$

J. L. Brenner, Zolotarev's theorem on the Legendre symbol ............... 413

Jospeh Atkins Childress, Jr., Restricting isotopies of spheres .............. 415

John Edward Coury, Some results on lacunary Walsh series ................ 419

James B. Derr and N. P. Mukherjee, Generalized Sylow tower groups. II . . . . . . 427

Paul Frazier Duvall, Jr., Peter Fletcher and Robert Allen McCoy, Isotopy Galois

spaces .......................................... 435

Mary Rodriguez Embry, Strictly cyclic operator algebras on a Banach space ... 443

Abi (Abiadbollah) Fattahi, On generalizations of Sylow tower groups ......... 453

Burton I. Fein and Murray M. Schacher, Maximal subfields of tensor products . . 479

Ervin Fried and J. Sichler, Homomorphisms of commutative rings with unit

element .......................................... 485

Kenneth R. Goodearl, Essential products of nonsingular rings ............. 493

George Grätzer, Bjarni Jónsson and H. Lakser, The amalgamation property in

equational classes of modular lattices ...........................

507

$\mathrm{H}$. Groemer, On some mean values associated with a randomly selected simplex

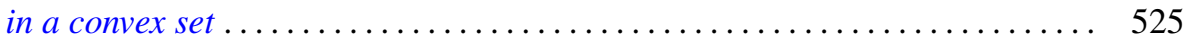

Marcel Herzog, Central 2-Sylow intersections .................... 535

Joel Saul Hillel, On the number of type-k translation-invariant groups ........ 539

Ronald Brian Kirk, A note on the Mackey topology for $\left(C^{b}(X)^{*}, C^{b}(X)\right) \ldots \ldots .543$

J. W. Lea, The peripherality of irreducible elements of lattice.............. 555

John Stewart Locker, Self-adjointness for multi-point differential operators ..... 561

Robert Patrick Martineau, Splitting of group representations ............... 571

Robert Massagli, On a new radical in a topological ring ................. 577

James Murdoch McPherson, Wild arcs in three-space. I. Families of Fox-Artin

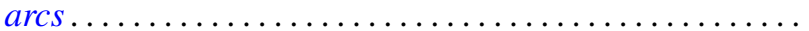

585

James Murdoch McPherson, Wild arcs in three-space. III. An invariant of

oriented local type for exceptional arcs . . . . . . . . . . . . ............ 599

Fred Richman, The constructive theory of countable abelian p-groups ........ 621

Edward Barry Saff and J. L. Walsh, On the convergence of rational functions

which interpolate in the roots of unity ..................

Harold Eugene Schlais, Non-aposyndesis and non-hereditary

decomposability..................................... 643

Mark Lawrence Teply, A class of divisible modules................... 653

Edward Joseph Tully, Jr., H-commutative semigroups in which each

homomorphism is uniquely determined by its kernel ................. 669

Garth William Warner, Jr., Zeta functions on the real general linear group ...... 681

Keith Yale, Cocyles with range $\{ \pm 1\} \ldots \ldots \ldots \ldots \ldots \ldots \ldots \ldots \ldots \ldots \ldots \ldots \ldots . \ldots \ldots$

Chi-Lin Yen, On the rest points of a nonlinear nonexpansive semigroup ........ 699 